\title{
BMJ Open A cross-sectional study on the relationship of age, gestational age and HIV infection to bacterial vaginosis and genital mycoplasma infection
}

\author{
Mathys J Redelinghuys, ${ }^{1}$ Marthie M Ehlers, ${ }^{1,2}$ Andries W Dreyer, ${ }^{3}$ \\ Hennie Lombaard, ${ }^{4}$ Steve A S Olorunju, ${ }^{5}$ Marleen M Kock ${ }^{1,2}$
}

To cite: Redelinghuys MJ, Ehlers MM, Dreyer AW, et al. A cross-sectional study on the relationship of age, gestational age and HIV infection to bacterial vaginosis and genital mycoplasma infection. BMJ Open 2015;5:e008530. doi:10.1136/bmjopen-2015008530

- Prepublication history for this paper is available online. To view these files please visit the journal online (http://dx.doi.org/10.1136/ bmjopen-2015-008530).

Received 17 April 2015

Revised 27 August 2015

Accepted 4 September 2015

CrossMark

For numbered affiliations see end of article.

Correspondence to

MJ Redelinghuys;

shanered72@gmail.com

\section{ABSTRACT}

Objectives: Pregnant women are especially at risk of developing complications when infected with reproductive tract infections (RTIs). The objective of this study was to determine the prevalence of bacterial vaginosis (BV) and genital mycoplasmas in pregnant women and investigate the associations between BV, genital mycoplasmas, HIV infection, age and gestational age.

Design: Cross-sectional study with descriptive and analytical components.

Setting: Antenatal clinic of a tertiary academic hospital in South Africa.

Participants: 220 pregnant women older than 18 were included in the study and provided self-collected vaginal swabs.

Primary and secondary outcomes: BV and genital mycoplasma colonisation and/or infection in women of differing age, gestational period and HIV status.

Results: The prevalence of BV was $17.7 \%$ (39/220) (95\% Cl 12.9 to 23.4), intermediate vaginal flora (IVF) $15 \%(33 / 220)(95 \% \mathrm{Cl} 10.56$ to 20.42$)$, and the overall prevalence of genital mycoplasmas was $84 \%$ $(185 / 220)(95 \%$ Cl 78.47 to 88.58$)$. BV was significantly associated with HIV infection with an $\mathrm{OR}$ of $2.84(95 \% \mathrm{Cl} 1.08$ to 7.46 and $p$ value $=0.034)$. However, BV was inversely associated with gestational age with an OR of $0.08(95 \% \mathrm{Cl} 0.01$ to 0.42 and $p$ value $=0.003$ ) for second trimester pregnancies and an OR of $0.03(95 \% \mathrm{Cl} 0.01$ to 0.17 and $p$ value $<0.001)$ for third trimester pregnancies using the first trimester as reference. IVF was significantly associated with HIV infection with an $\mathrm{OR}$ of $2.7(95 \% \mathrm{Cl} 1.07$ to 6.79 and $\mathrm{p}$ value $=0.035$ ) but not with age or gestational age. Genital mycoplasmas were not significantly associated with age, gestational age, HIV status, BV flora or IVF.

Conclusions: The high infection rate of genital mycoplasmas and the association of BV with HIV found in this study reiterate the importance of screening for these RTIs in high-risk groups such as pregnant women.

\section{INTRODUCTION}

Bacterial vaginosis (BV) is a dysbiosis of the vagina and is the most common cause of

\section{Strengths and limitations of this study}

This study reports the prevalence of and associations between vaginal flora, genital mycoplasmas, age and gestational age in women attending antenatal care in an HIV endemic setting.

- The large sample size included women from a wide age range and gestational age range.

- No patient follow-up was performed to record downstream infection and/or colonisation status to investigate the dynamics of such infections during the course of pregnancy; hence, pregnancy outcome was also not measured.

vaginal discharge in women of childbearing age. ${ }^{1}$ The prevalence of $\mathrm{BV}$ ranges from $10 \%$ to $50 \%$ during pregnancy across the world. $^{2-4}$ Genital mycoplasmas, including Mycoplasma hominis, M. genitalium, Ureaplasma parvum and $U$. urealyticum may reach colonisation rates of even up to $80 \%$ in healthy, sexually active women. ${ }^{5}$ Mycoplasma infections are often elusive or subclinical in nature, and it is not always possible to prove the pathogenic nature of these bacteria. ${ }^{6}$ Genital mycoplasmas are primarily transmitted via sexual contact. ${ }^{7} 8$ Transmission may, however, be vertical from mother to offspring, either in utero or during the passage through the birth canal. ${ }^{9}$

Genital mycoplasmas may travel from the vagina and penetrate the amniotic membranes to produce inflammation that results in pregnancy complications. ${ }^{10}{ }^{11}$ These ascending infections may be enhanced by $\mathrm{BV}^{12}$ Genital mycoplasmas are the most frequently isolated bacteria in women who present with chorioamnionitis as these are responsible for $45 \%$ of such cases. ${ }^{10} \mathrm{BV}$, especially when $G$. vaginalis or $M$. hominis and $U$. urealyticum are cultured, is associated with a fivefold increased risk of pregnancy loss. ${ }^{13}$ These reproductive tract infections (RTIs) 
are implicated in medical conditions, such as pelvic inflammatory disease (PID), preterm premature rupture of membranes, preterm birth (PTB), pregnancy loss and postpartum and postabortal sepsis. ${ }^{4} 5$ 14-16 Infection with $\mathrm{BV}$ and genital mycoplasmas may increase the risk of HIV acquisition and the rates of HIV shedding in the genital tract. ${ }^{17-21}$ In this way, BV and genital mycoplasma infections may contribute notably to morbidity and mortality. The clinical course of conventional RTIs may also be modified by HIV infection and this complicates the diagnosis and treatment of these infections. ${ }^{22}$

Although effective treatment options are available, the treatment of $\mathrm{BV}$ is complicated when infection status is unknown, as screening for BV-related bacteria is not the standard of care and not routinely performed. The lack of screening for these bacteria is a matter of concern in pregnant women who are at risk of developing pregnancy complications, especially in developing countries. In many of these countries, syndromic management is used to treat RTIs, but this approach is complicated by the large number of asymptomatic infections. ${ }^{23}$ Even though there is no clear evidence of the advantages from screening or treatment of all women who have asymptomatic $\mathrm{BV}$, evidence suggests that screening and treatment in pregnant women may reduce PTB and low birthweight infants. ${ }^{24} 25$

The purpose of the study was to determine the prevalence of BV and genital mycoplasmas in a population of HIV-positive and HIV-negative pregnant women attending antenatal care, and to determine the associations between BV, genital mycoplasmas, HIV infection, age and gestational age.

\section{METHODS}

Study design, setting and population

This is a descriptive, cross-sectional study with an analytical component. The study was conducted at the Department of Medical Microbiology, University of Pretoria, South Africa. Continuous participant recruitment and sample collection were carried out from July 2012 to December 2012, and laboratory procedures were conducted from July 2012 to March 2013. Samples were obtained from pregnant women attending the antenatal clinic of a tertiary academic hospital in Pretoria, Gauteng, South Africa. Criteria for inclusion into the study were: pregnant woman of any gestational period, older than 18 years of age, who gave informed consent to participate in the study, and who have not taken any antimicrobial agents 30 days prior to sample collection. All the participants gave written informed consent prior to enrolment and sample collection. Available medical information from the participants, such as rapid plasma reagin (RPR) status, current medication, HIV status (as tested by the hospital with a First Response HIV 1-2.0 card rapid test (Premier Medical Corporation Ltd, Daman, India); tests performed twice to confirm results) and current gestational age was recorded. Gestational age was divided into three stages: first trimester ( $\leq 12$ weeks pregnant), second trimester (13 weeks to 26 weeks pregnant) and third trimester (27-40 weeks pregnant).

\section{Sample collection and processing}

Two self-collected vaginal swabs, a dry swab and an ESwab (a flocked nylon swab containing $1 \mathrm{~mL}$ modified Amies transport medium (Copan Diagnostics, Inc, Italy) were obtained from every participant. The order in which the swabs were obtained was alternated between women. The women were instructed to swirl the swab once and to keep it inside the vagina for $10 \mathrm{~s}$ to absorb vaginal fluid. Immediately after collection, the dry swab was used to make a smear on a glass slide (B\&C, Germany) and left to air dry, while the ESwab was used to seed $1 \mathrm{~mL}$ of Amies transport medium and stored on ice. The swabs were kept on ice and transported to the laboratory within 1-4 h, and were then processed for further analyses, while the vaginal smears were transported dry.

\section{Microscopy}

The dry vaginal smears were fixed to the slides by heating for $5 \mathrm{~s}$ using a Bunsen burner, followed by Gram-staining. Gram-stained smears were subsequently graded with the Nugent scoring system as described by Nugent et $a l^{26}$ Based on the resulting Nugent scores, the vaginal flora were categorised as normal vaginal flora (NVF; scores 0-3), intermediate vaginal flora (IVF) (scores 4-6), or BV flora (scores 7-10).

\section{Molecular detection of genital mycoplasmas}

DNA extraction from modified Amies transport medium

Bacterial DNA was isolated from the vaginal swabs with the ZR Fungal/Bacterial DNA kit (Zymo Research, USA) according to the manufacturer's instructions. A volume of $150 \mu \mathrm{L}$ seeded Amies transport medium (Copan Diagnostics, Inc, Italy) was used to extract bacterial DNA. One hundred microlitres of ultra-pure DNA was eluted and stored at $-20^{\circ} \mathrm{C}$ until further analysis.

\section{Amplification of human $\beta$-globin gene}

Each sample was subjected to an internal positive control $\beta$-globin PCR assay to ensure that amplifiable DNA was successfully extracted from the sample, to monitor for PCR inhibitors, and to exclude falsenegative results. ${ }^{27}$ The oligonucleotide primer sequences used were obtained from Martin et al. ${ }^{28}$ All $\beta$-globin gene PCRs were performed using the EmeraldAmp GT PCR Master Mix (Takara Biotechnology, Japan) in a Gradient MasterCycler (Eppendorf, Hamburg, Germany) according to the manufacturer's instructions. The amplification programme comprised an initial denaturation step at $95^{\circ} \mathrm{C}$ for $15 \mathrm{~min}, 40$ cycles of three steps including denaturation at $95^{\circ} \mathrm{C}$ for $30 \mathrm{~s}$, annealing at $56^{\circ} \mathrm{C}$ for $45 \mathrm{~s}$ and extension $72^{\circ} \mathrm{C}$ for $1 \mathrm{~min}$, followed by a final extension step at $72^{\circ} \mathrm{C}$ for $7 \mathrm{~min}$. 
Multiplex-PCR assay for the detection of genital mycoplasmas

The samples that were positive for the $\beta$-globin gene were subjected to a multiplex PCR assay to determine the presence of M. genitalium, M. hominis, U. parvum and $U$. urealyticum. The multiplex PCR assay was adapted from the method used by Stellrecht et al. ${ }^{29}$ The primers used in this assay targeted the $140 \mathrm{kDa}$ adhesion protein of $M$. genitalium, the $16 \mathrm{~S}$ rRNA of $M$. hominis and multiple-banded antigen (MBA) genes of $U$. parvum and $U$. urealyticum. The multiplex PCR assay was validated with the AmpliRun Mycoplasma genitalium DNA control (Vircell SL, Spain), a positive M. hominis sample isolated with A2 agar and reference strains ATCC 27813 (U. parvum) and ATCC 27619 (U. urealyticum). The Qiagen multiplex PCR kit (Qiagen, Germany) was used according to the manufacturer's instructions. Amplification was performed in a Gradient MasterCycler (Eppendorf, Hamburg, Germany) using the following conditions: 1 cycle of $15 \mathrm{~min}$ at $95^{\circ} \mathrm{C}$, followed by 40 three-step cycles at $94^{\circ} \mathrm{C}$ for $30 \mathrm{~s}, 60^{\circ} \mathrm{C}$ for $90 \mathrm{~s}$ and $72^{\circ}$ $\mathrm{C}$, followed by a final extension of $10 \mathrm{~min}$ at $72^{\circ} \mathrm{C}$.

\section{Statistical analysis}

Categorical data were expressed as percentages. Continuous variables were reported using measures of central tendency and dispersion; for normally distributed data, the mean and SD were used to describe the data. Statistical analyses were performed using STATA V.13.1. Associations were assessed using contingency tables for different variables. A $p$ value of $<0.05$ was considered significant. Further evaluation was carried out using univariate logistic regression for each dependent outcome with the factors (independent), with a $95 \%$ CI. Univariate logistic regression was followed by a multivariable logistic regression analysis to adjust for potential confounders. Only variables that were significant (ie, $p$ value $<0.05$ ) in the univariate analyses were included in the multivariable analysis. Multinomial logistic regression was carried out for the vaginal flora categories, including NVF (reference category), IVF and BV. Vaginal flora categories (IVF and BV) and genital mycoplasmas were dependent variables whereas age, gestational age and HIV infection were the independent variables. Furthermore, genital mycoplasmas were used as the independent variable to measure associations between the vaginal flora categories and individual genital mycoplasma species. The test of multicollinearity was also evaluated using the variance inflation factor (vif). In addition, generally STATA has an inbuilt system of assessing multicollinearity in model fitting. Wherever multicollinearity exists, the parameter is dropped out automatically.

\section{RESULTS}

Two hundred and twenty pregnant women were included in this study. The mean age of the population sampled was $30 \pm 5.95$ years. The mean gestational age of current pregnancies of participating women was 26 \pm 7.97 weeks. All 220 samples tested positive for the human $\beta$-globin gene and all participating women had a negative RPR status. The HIV status of 201 out of 220 women was available and included 36 HIV-positive women. All the HIV-related statistical analyses were carried out according to this subset of women.

A total of $39(17.7 \%)$ (95\% CI $12.9 \%$ to $23.4 \%)$ women had BV flora while $33(15 \%)(95 \%$ CI $10.56 \%$ to $20.42 \%)$ women had IVF and $148(67.3 \%)$ (95\% CI $60.67 \%$ to $73.45 \%$ ) women had NVF. BV was detected in $9(25 \%)$ of 36 HIV-positive women, and in $26(15.8 \%)$ of 165 HIV-negative women. IVF was also detected in 9 (25\%) of 36 HIV-positive women and in 22 (13.3\%) of 165 HIV-negative women. BV and IVF were significantly associated with HIV infection with respective ORs of 2.84 (95\% CI 1.08 to 7.46 and $\mathrm{p}$ value $=0.034$ ) and 2.7 (95\% CI 1.07 to 6.79 and $p$ value $=0.035$ ). Women of age 18 to 24 had the highest proportion of BV infection (20.4\%) (95\% CI 10.24 to 34.34). In addition, BV was inversely associated with gestational age with an OR of 0.08 (95\% CI 0.01 to 0.42 and $p$ value $=0.003)$ for second trimester pregnancies, and an OR of 0.03 (95\% CI 0.01 to 0.17 and $p$ value $<0.001$ ) for third trimester pregnancies, the first trimester being used as reference. BV and IVF were positively associated with age; however, none of these associations were statistically significant.

The results of the multiplex PCR assay indicated that M. hominis was isolated from $111(50.4 \%) \quad(95 \%$ CI $43.60 \%$ to $57.19 \%$ ) samples, M. genitalium from 33 (15\%) (95\% CI $10.56 \%$ to $20.42 \%)$ samples, $U$. parvum from $157(70.2 \%)$ (95\% CI $63.68 \%$ to $76.16 \%$ ) samples, and $U$. urealyticum from $5(2.8 \%)(95 \%$ CI $1.05 \%$ to $5.94 \%)$ samples. The positivity rate for samples with at least one genital mycoplasma species present was $84 \%$ (185/220) (95\% CI $78.47 \%$ to $88.58 \%)$. There was no significant difference in mycoplasma colonisation across the three trimesters (table 1) of pregnancy or with increasing age (table 2). Ureaplasma urealyticum was not included in the tables because there were not enough observations in the different categories for comparison.

Thirty-eight out of 39 samples (97\%) with a high Nugent score $\geq 7$ (BV positive), and 27 out of 33 samples $(81.8 \%)$ with an intermediate Nugent score (4-6) were positive for at least one genital mycoplasma species. In samples with a Nugent score of $\geq 7$, U. parvum was detected in $33(84.6 \%)$, M. hominis in 28 $(71.8 \%)$, M. genitalium in $7(17.9 \%)$ and $U$. urealyticum in $1(2.7 \%)$ sample. In samples with an intermediate Nugent score, $U$. parvum was detected in $22(66.7 \%)$, M. hominis in 18 (54.5\%), M. genitalium in $5(15.2 \%)$ and $U$. urealyticum in $1(3 \%)$ sample. Fisher's exact test showed no association between BV and individual mycoplasmas (Ureaplasma parvum ( $\mathrm{p}$ value $=0.139$ ), M. hominis ( $\mathrm{p}$ value $=0.954), M$. genitalium $(\mathrm{p}$ value $=0.183)$ and $U$. urealyticum ( $\mathrm{p}$ value $=0.585)$ ). In the HIV-positive group, Ureaplasma parvum was detected in 26 (72.2\%), 
Table 1 Distribution of BV, IVF and genital mycoplasmas across each trimester of pregnancy in pregnant women attending antenatal care

Gestational age

Trimester 1 ( $n=13)$

(Reference) Trimester $2(\mathrm{n}=98)$

Reproductive tract

Prevalence

Prevalence

infection

(\%)

OR (\%)

BV

$8(61.5)$

IV flora

1 (7.6)

M. genitalium

$1(7.6)$

M. hominis

$5(38.5)$

U. parvum

9 (69.2)

$21(21.4)$

$13(13.3)$

13 (13.3)

$51(52)$

67 (67.4)

=98)

Trimester $3(n=109)$

Prevalence Total

$\mathrm{BV}$, bacterial vaginosis; IVF, intermediate vaginal flora.

(\%)

$10(9.2) \quad 0.03(0.01$ to 0.17$) \quad<0.001$

$0.08(0.01$ to 0.42$) \quad 0.003$

$0.33(0.03$ to 4.11$) \quad 0.396$

$1.84(0.22$ to 15.32$) \quad 0.575$

$1.74(0.53$ to 5.68$) \quad 0.362$

$0.96(0.27$ to 3.36$) \quad 0.950$

$19(17.4)$

$0.44(0.04$ to 5.11$)$

$1.63(0.50$ to 5.30$)$

$81(74.3)$

$1.29(0.37$ to 4.50$)$

0.694

$(\mathrm{n}=220)$

39

33

33

111

157

Table 2 Distribution of BV, IVF and genital mycoplasmas across three age categories in pregnant women attending antenatal care

\begin{tabular}{|c|c|c|c|c|c|c|c|c|c|}
\hline \multirow[b]{3}{*}{ Reproductive tract infection } & \multicolumn{9}{|l|}{ Age category } \\
\hline & \multicolumn{2}{|c|}{$\begin{array}{l}\text { 18-24 years }(n=49) \\
\text { (Reference) }\end{array}$} & \multicolumn{3}{|c|}{$25-34$ years $(n=120)$} & \multicolumn{3}{|c|}{$>35$ years $(n=51)$} & \multirow[b]{2}{*}{ Total $(n=220)$} \\
\hline & Prevalence (\%) & OR & Prevalence (\%) & OR and $95 \% \mathrm{Cl}$ & p Value & Prevalence (\%) & OR and $95 \% \mathrm{Cl}$ & p Value & \\
\hline BV & $10(20.4)$ & 1 & $20(16.7)$ & $1.21(0.42$ to 3.48$)$ & 0.726 & $9(17.6)$ & $1.15(0.32$ to 4.06$)$ & 0.831 & 39 \\
\hline IV flora & 6 (12.2) & 1 & $18(15)$ & 1.25 (0.44 to 3.54$)$ & 0.679 & $9(17.6)$ & $1.54(0.47$ to 5.15$)$ & 0.475 & 33 \\
\hline M. genitalium & $9(18.4)$ & 1 & $16(13.3)$ & 0.78 (0.29 to 2.09$)$ & 0.615 & $8(15.7)$ & $1.27(0.41$ to 3.93$)$ & 0.674 & 33 \\
\hline M. hominis & $26(53.1)$ & 1 & $63(52.5)$ & 0.56 (0.28 to 1.12$)$ & 0.102 & $22(43.1)$ & 0.69 (0.30 to 1.62$)$ & 0.398 & 111 \\
\hline U. parvum & $42(85.7)$ & 1 & $81(67.5)$ & 0.81 (0.38 to 1.73$)$ & 0.583 & $34(66.7)$ & $1.72(0.63$ to 4.74$)$ & 0.291 & 157 \\
\hline
\end{tabular}

$\mathrm{BV}$, bacterial vaginosis; IVF, intermediate vaginal flora.

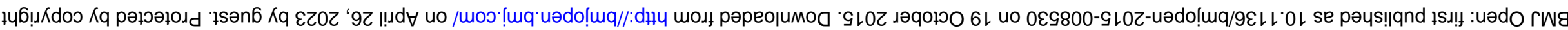


M. hominis in $27(75 \%)$, M. genitalium in $8(22.2 \%)$ and $U$. urealyticum in $2(5.5 \%)$ women. However, none of these results were significantly different from that respectively observed among HIV-negative women; in the HIV-negative group, Ureaplasma parvum was detected in $117(70.9 \%)$, M. hominis in $74(44.8 \%)$, M. genitalium in $22(13.3 \%)$ and $U$. urealyticum in $2(1.2 \%)$ women.

\section{DISCUSSION}

In this study, the prevalence of RTIs in pregnant women was high. BV was present in $17 \%$ of the pregnant women and was more strongly associated with the early stages of pregnancy. In addition, BV flora was more common in HIV-positive women. All the mycoplasma species, except for $U$. urealyticum, were present in higher numbers in samples with a high Nugent score $(\geq 7)$ as compared to samples with an intermediate Nugent score (4-6). Ureaplasma parvum was the most commonly isolated species and contributed to the high prevalence of genital mycoplasmas found in this study.

This study describes the prevalence of and associations between BV and genital mycoplasmas in women attending antenatal care in an HIV-endemic setting. The study sample size was adequate with a good representation of pregnant women from a wide age range and gestational age range. The investigators failed to discriminate between symptomatic and asymptomatic women with regard to BV. The symptoms that women reported were vague and subjective. Most women could not distinguish between a discharge characteristic of BV or a physiological discharge. Some women described having a discharge that might have been more characteristic of other vaginal infections, such as those caused by Candida spp. or Trichomonas vaginalis. However, vaginal samples were not assessed for any other RTIs apart from BV and genital mycoplasmas. The prevalence of RTIs found in this study was just a snapshot in time; no follow-up of patients was carried out (which is a problem with cross-sectional studies in general). It was, therefore, difficult to make any causal inferences. Nonetheless, the data available allowed sufficient conclusions to be drawn.

The prevalence of BV found in this study corresponds to the prevalence rates of 5\% to $25 \%$ in (asymptomatic) pregnant women reported by Tolosa et al. ${ }^{30}$ The association between BV and HIV reported by Myer $e t a l^{31}$ was confirmed in this study. Bayraktar et $a \vec{l}^{2}$ reported a prevalence of $29 \%$ for genital mycoplasmas in Turkey, using A7 agar to determine the presence of $M$. hominis and $U$. urealyticum. Koh $e t a l^{33}$ used the Mycoplasma IST-2 kit to detect these two species and found a prevalence of $44.2 \%$ in South Korea. The overall prevalence of genital mycoplasmas in the present study (as determined by PCR) was high (84\%) when compared to these two studies. The higher prevalence obtained with a molecular method is expected as this method is more sensitive than culture tests. However, molecular methods detect viable and non-viable bacteria, and do not indicate current infection/colonisation. There are contentious reports on the prevalence of Ureaplasma spp. De Francesco et $a l^{34}$, Povlsen $e t a l^{35}$ and Kataoka et $a l^{15}$ reported $U$. parvum to be the most prevalent genital mycoplasma in reproductive-age women (prevalence rates of $17-64 \%)$, whereas Koh et $a l^{33}$ and Zdrodowska-Stefanow et $a l^{7}$ reported $U$. urealyticum to be the most prevalent genital mycoplasma, with prevalence rates of 22-39\%. Many studies that investigated ureaplasmas did not discriminate between the two different species $^{532}$ as was carried out in this study. The results reported by these studies may have given a skewed representation of infection rates. Although $U$. urealyticum has been implicated in more pathogenic cases, inconsistent findings exist as to which Ureaplasma species is the most pathogenic. ${ }^{15} 36$ M. hominis is present in $58-76 \%$ of women with $\mathrm{BV}$, and $U$. urealyticum in $62-92 \%$ of women with $\mathrm{BV}^{37}$ The findings of $M$. hominis in the present study are similar to what $\mathrm{Hill}^{37}$ reported as this species was present in $71.7 \%$ of women with BV. This association was, however, not significant and is supported by Keane et $a l .{ }^{38}$ The present study's finding agrees with the findings of Govender ${ }^{39}$ in 2010, who reported no association between the colonisation of M. hominis and HIV status. The prevalence of M. genitalium found in this study corresponded with other studies ${ }^{40-43}$ that reported a prevalence rate of 3-26.3\% in women. Although information on the adverse effects of $M$. genitalium in pregnancy is limited, there may be an association between $M$. genitalium infection and preterm birth (PTB) in pregnancy. ${ }^{43}$

The high prevalence of RTIs found in this study increases the risk for women and their unborn babies to develop health problems. This increased risk is a result of potential ascending infections and eventually poor pregnancy outcomes. Infectious agents involved in ascending infections may be passed on to babies during pregnancy or birth, and result in neonatal death, sepsis, pneumonia and stillbirth. ${ }^{44}$ In addition, undetected and untreated infections can lead to PID, which may lead to infertility or ectopic pregnancies. ${ }^{44}$ These complications will lead to an increased demand for healthcare assistance and an unnecessary downstream of financial burdens. These RTIs also increase the risk of acquiring other infections, including HIV, up to threefold. ${ }^{44}$ Women who are already HIV-positive and have untreated BV infections are at risk of having higher mucosal HIV viral loads (HIV shedding) because BV flora may upregulate viral replication through a heat-stable HIV-inducing factor. ${ }^{45-49}$ The increased shedding of virus particles translates to increased sexual partner infections and babies born with complications.

The potential impacts of highly prevalent BV and genital mycoplasmas should be investigated in more defined populations, focusing on maternal and fetal health. These populations can include women with recent adverse pregnancy outcomes, or a large pregnant and HIV-positive cohort. This study could be improved by conducting an outcome-based study within two or more 
different time frames where pregnant women are followed up. Practitioner-collected swabs may be better to correlate symptoms with specific infections, especially if the efficacy of antibiotics and pregnancy outcomes are investigated. The non-significant trend of younger women to be infected with BV and genital mycoplasmas indicates the need to focus on younger age groups to inform and educate them on the risks and preventative measures of RTIs. In resource-poor countries, the potential to screen all women for most RTIs is expensive and not always feasible. ${ }^{50}$ Based on the main study findings, it is recommended that studies assess the advantage of screening pregnant women for BV and genital mycoplasmas, at least at the first antenatal visit to the clinic (ie, targeted screening in a high-risk group). This screening approach could help identify asymptomatic cases and correctly identify symptomatic cases; combined with the correct treatment regimen, this screening may reduce pregnancy complications and HIV genital viral load in HIV-positive women. ${ }^{4}{ }^{51}$

\section{Author affiliations}

${ }^{1}$ Department of Medical Microbiology, University of Pretoria, Pretoria, South Africa

${ }^{2}$ Department of Medical Microbiology, Tshwane Academic Division, National Health Laboratory Service, Pretoria, South Africa

${ }^{3}$ Centre for Tuberculosis, National Institute for Communicable Diseases, Johannesburg, South Africa

${ }^{4}$ Department of Obstetrics and Gynaecology, University of Pretoria, Pretoria, South Africa

${ }^{5}$ Biostatistics Unit, South African Medical Research Council, Pretoria, South Africa

\section{Twitter Follow Mathys Redelinghuys at @Shanered72}

Contributors MJR is the project leader and was involved in concept design, sample procurement, laboratory work, data analysis and writing of the manuscript. MMK is the principal investigator and grant holder. MMK and MME were involved in the conceptual design of the study as well as review of the manuscript. AWD contributed towards the clinical aspect of the study and was involved in review of the manuscript. HL was involved in the conceptual design of the study as well as in overseeing the logistics of sample procurement. SASO was involved in data and statistical analysis. All authors read and approved the final manuscript.

Funding The work was supported by funding received by MMK from the University of Pretoria and the Medical Research Council (South Africa). The views and findings expressed in this manuscript are those of the authors and are not necessarily shared or supported by the Medical Research Council.

Competing interests None declared.

Ethics approval This study was approved by the Student Research Ethics Committee of the University of Pretoria (approved protocol number S6/2012).

Provenance and peer review Not commissioned; externally peer reviewed.

Data sharing statement No additional data are available.

Open Access This is an Open Access article distributed in accordance with the Creative Commons Attribution Non Commercial (CC BY-NC 4.0) license, which permits others to distribute, remix, adapt, build upon this work noncommercially, and license their derivative works on different terms, provided the original work is properly cited and the use is non-commercial. See: http:// creativecommons.org/licenses/by-nc/4.0/

\section{REFERENCES}

1. Sobel JD, Ferris D, Schwebke J, et al. Suppressive antibacterial therapy with $0.75 \%$ metronidazole vaginal gel to prevent recurrent bacterial vaginosis. Am J Obstet Gynaecol 2006;194:1283-9.
2. Cammack AL, Buss C, Entringer S, et al. The association between early life adversity and bacterial vaginosis during pregnancy. $A m J$ Obstet Gynaecol 2011;204:431.e1-8.

3. Govender L, Hoosen AA, Moodley J, et al. Bacterial vaginosis and associated infections in pregnancy. Int J Gynaecol Obstet 1996;55:23-8.

4. Guerra B, Ghi T, Quarta S, et al. Pregnancy outcome after early detection of bacterial vaginosis. Eur J Obstet Gynaecol Reprod Biol 2006;128:40-5.

5. Kechagia N, Bersimis S, Chatzipanagiotou S. Incidence and antimicrobial susceptibilities of genital mycoplasmas in outpatient women with clinical vaginitis in Athens, Greece. J Antimicrob Chemother 2008;62:122-5.

6. Sung $\mathrm{H}$, Kang $\mathrm{SH}, \mathrm{Bae} \mathrm{YJ}$, et al. PCR-based detection of Mycoplasma species. J Microbiol 2006;44:42-9.

7. Zdrodowska-Stefanow B, Klosowska WM, Ostaszewska-Puchalska I, et al. Ureaplasma urealyticum and Mycoplasma hominis infection in women with urogenital diseases. Adv Med Sci 2006;51:250-3.

8. Gdoura R, Kchaou W, Chaari C, et al. Ureaplasma urealyticum, Ureaplasma parvum, Mycoplasma hominis and Mycoplasma genitalium infections and semen quality of infertile men. BMC Infect Dis 2007;7:129.

9. Volgmann T, Ohlinger R, Panzig B. Ureaplasma urealyticumharmless commensal or underestimated enemy of human reproduction? A review. Arch Gynecol Obstet 2005;273: 133-9.

10. Allanson B, Jennings $B$, Jacques $A$, et al. Infection and foetal loss in the mid-second trimester of pregnancy. Aust N Z J Obstet Gynaecol 2010:50:221-5.

11. Galask RP, Varner MW, Petzold CR, et al. Bacterial attachment to the chorioamniotic membranes. Am J Obstet Gynecol 1984;148:915-28.

12. McDonald HM, Brocklehurst P, Gordon A. Antibiotics for treating bacterial vaginosis in pregnancy. Cochrane Database of Syst Rev 2007;(1):CD000262.

13. Donders GG, Van Bulck B, Caudron J, et al. Relationship of bacterial vaginosis and mycoplasmas to the risk of spontaneous abortion. Am J Obstet Gynaecol 2000;183:431-7.

14. Vogel I, Thorsen P, Hogan VK, et al. The joint effect of vaginal Ureaplasma urealyticum and bacterial vaginosis on adverse pregnancy outcomes. Acta Obstet Gynecol 2006;85:778-85.

15. Kataoka S, Yamada T, Chou K, et al. Association between preterm birth and vaginal colonization by mycoplasmas in early pregnancy. $J$ Clin Microbiol 2006;44:51-5.

16. Kacerovsky M, Pliskova L, Bolehovska R, et al. The microbial load with genital mycoplasmas correlates with the degree of histologic chorioamnionitis in preterm PROM. Am J Obstet Gynecol 2011;205:213.e1-7.

17. O'Farrell N, Windsor I, Becker P. HIV-1 infection among heterosexual attenders at a sexually transmitted diseases clinic in Durban. S Afr Med J 1991;80:17-20.

18. Sagar M, Lavreys L, Baeten JM, et al. Identification of modifiable factors that affect the genetic diversity of the transmitted HIV-1 population. AIDS 2004;18:615-19.

19. Montagnier L, Blanchard A. Mycoplasmas as cofactors in infection due to the human immunodeficiency virus. Clin Infect Dis 1993;17: S309-15.

20. Hashimoto O, Yoshida $\mathrm{T}$, Ishiko $\mathrm{H}$, et al. Quantitative detection and phylogeny-based identification of mycoplasmas and ureaplasmas from human immunodeficiency virus type 1-positive patients. $J$ Infect Chemother 2006;12:25-30.

21. Woodman Z, Mlisana K, Treurnicht F, et al. Decreased incidence of dual infections in South African subtype C-infected women compared to a cohort 19 years earlier. AIDS Res Hum Retroviruses 2011;27:1167-72.

22. Rours GIJG, Verkooyen RP, Hop WCJ, et al. Sexually transmitted infections in pregnant urban South-African women: Socio-economic characteristics and risk factors. South Afr J Epidemiol Infect 2006;21:14-19.

23. Romoren $\mathrm{M}$, Velauthapillai $\mathrm{M}$, Rahman $\mathrm{M}$, et al. Trichomoniasis and bacterial vaginosis in pregnancy: inadequately managed with the syndromic approach. Bull World Health Organ 2007;85:297-304.

24. Farquharson RG, Jauniaux E, Exalto N. Updated and revised nomenclature for description of early pregnancy events. Hum Reprod 2005;20:3008-11.

25. Swadpanich U, Lumbiganon $\mathrm{P}$, Prasertcharoensook W, et al. Antenatal lower genital tract infection screening and treatment programs for preventing preterm delivery. Cochrane Database Syst Rev 2008;(2):CD006178. 
26. Nugent RP, Krohn MA, Hillier SL. Reliability of diagnosing bacterial vaginosis is improved by a standardized method of gram stain interpretation. J Clin Microbiol 1991;29:297-301.

27. Bradshaw CS, Tabrizi SN, Fairley CK, et al. The association of Atopobium vaginae and Gardnerella vaginalis with bacterial vaginosis and recurrence after oral metronidazole therapy. $J$ Infect Dis 2006;194:828-36.

28. Martin IE, Tsang RSW, Sutherland K, et al. Molecular characterisation of syphilis in patients in Canada: azithromycin resistance and detection of Treponema pallidum DNA in whole-blood samples versus ulcerative swabs. J Clin Microbiol 2009;47:1668-73.

29. Stellrecht KA, Woron AM, Mishrik NG, et al. Comparison of multiplex PCR assay with culture for detection of genital mycoplasmas. J Clin Microbiol 2004;42:1528-33.

30. Tolosa JE, Chaithongwongwatthana S, Daly S, et al. The International Infections in Pregnancy (IIP) study: variations in the prevalence of bacterial vaginosis and distribution of morphotypes in vaginal smears among pregnant women. Am J Obstet Gynaecol 2006;195:1198-204.

31. Myer L, Denny L, Telerant R, et al. Bacterial vaginosis and susceptibility to HIV infection in South African women: a nested case-control study. J Infect Dis 2005;192:1372-80.

32. Bayraktar MR, Ozerol IH, Gucluer N, et al. Prevalence and antibiotic susceptibility of Mycoplasma hominis and Ureaplasma urealyticum in pregnant women. Int $J$ Infect Dis 2010;14:2.e90-5.

33. Koh E, Kim S, Kim I, et al. Antimicrobial susceptibilities of Ureaplasma urealyticum and Mycoplasma hominis in pregnant women. J Clin Microbiol 2009;12:159-62.

34. De Francesco MA, Negrini R, Pinsi G, et al. Detection of Ureaplasma biovars and polymerase chain reaction-based subtyping of Ureaplasma parvum in women with or without symptoms of genital infections. Eur J Clin Microbiol Infect Dis 2009;28:641-6.

35. Povlsen K, Thorsen P, Lind I. Relationship of Ureaplasma urealyticum biovars to the presence or absence of bacterial vaginosis in pregnant women and to the time of delivery. Eur J Clin Microbiol Infect Dis 2001;20:65-7.

36. Govender S, Theron GB, Odendaal HJ, et al. Prevalence of genital mycoplasmas, ureaplasmas and Chlamydia in pregnancy. J Obstet Gynaecol 2009;29:698-701.

37. Hill GB. The microbiology of bacterial vaginosis. Am J Obstet Gynaecol 1993;169:450-4.

38. Keane FE, Thomas BJ, Gilroy CB, et al. The association of Chlamydia trachomatis and Mycoplasma genitalium with non-gonococcal urethritis: observations on heterosexual men and their female partners. Int J STD AIDS 2000;11:435-9.

39. Govender S. Epidemiology and antibiotic susceptibility patterns of Mycoplasma spp. and Ureaplasma urealyticum [PhD thesis]. University of Stellenbosch; 2010.

40. Short VL, Jensen JS, Nelson DB, et al. Mycoplasma genitalium among young, urban pregnant women. Infect Dis Obstet Gynaecol 2010;2010:984760.

41. Pepin J, Labbe AC, Khonde $\mathrm{N}$, et al. Mycoplasma genitalium: an organism commonly associated with cervicitis among West African sex workers. Sex Transm Infect 2005;81:67-72.

42. Tosh AK, Van Der Pol B, Fortenberry JD, et al. Mycoplasma genitalium among adolescent women and their partners. J Adolesc Health 2007;40:412-17.

43. Hitti J, Garcia P, Totten P, et al. Correlates of cervical Mycoplasma genitalium and risk of preterm birth among Peruvian women. Sex Transm Dis 2010;37:81-5.

44. World Health Organization. Fact sheet $N^{\circ} 110$ : sexually transmitted infections (STIs). Geneva, Switzerland. http://whqlibdoc.who.int/ publications/2005/9241592656.pdf (accessed Oct 2014).

45. Johnson LF, Lewis DA. The effect of genital tract infections on HIV-1 shedding in the genital tract: a systematic review and meta-analysis. Sex Transm Dis 2008;35:946-59.

46. Zariffard MR, Novak RM, Lurain N, et al. Induction of tumour necrosis factor-alpha secretion and toll-like receptor 2 and 4 mRNA expression by genital mucosal fluids from women with bacterial vaginosis. J Infect Dis 2005;191:1913-21.

47. Coleman JS, Hitti J, Bukusi EA, et al. Infectious correlates of HIV-1 shedding in the female upper and lower genital tracts. AIDS 2007;21:755-9.

48. Taha TE, Hoover DR, Dallabetta GA, et al. Bacterial vaginosis and disturbances of vaginal flora: association with increased acquisition of HIV. AIDS 1998;12:1699-706.

49. Sha BE, Chen HY, Wang QJ, et al. Utility of Amsel criteria, Nugent score, and quantitative PCR for Gardnerella vaginalis, Mycoplasma hominis, and Lactobacillus spp. for diagnosis of bacterial vaginosis in human immunodeficiency virus-infected women. J Clin Microbiol 2005;43:4607-12.

50. Low N, Broutet N, Adu-Sarkodie Y, et al. Global control of sexually transmitted infections. Lancet 2006;368:2001.

51. Pilcher CD, Eron JJ, Galvin S, et al. Acute HIV revisited: new opportunities for treatment and prevention. J Clin Invest 2004;113:937-45. 